\title{
MECHANICAL PROPERTIES OF AISI 316 STEEL PREPARED BY 3D PRINTING
}

\author{
${ }^{1}$ Martin KRAUS, ${ }^{2}$ Vratislav MAREŠ \\ 1VSB-TU Ostrava, FMT, Ostrava, Czech Republic, EU, martin.kraus@vsb.cz \\ ${ }^{2}$ Center of Advanced Innovation Technologies - VSB-Technical University of Ostrava, Ostrava, Czech \\ Republic,EU, vratislav.mares@vsb.cz
}

https://doi.org/10.37904/metal.2019.854

\begin{abstract}
At present time is increasingly applying 3D printing methods in the area of production of metallic materials also. 3D printing is use for serial and individual unit production in the aerospace, automotive and medical applications (prosthetics, implants, etc.). 3D printing methods are chosen especially for the production of dimensionally complicated products, where is difficult or impossible to achieve a result by classical methods of production. In the case of steels, the austenitic stainless materials with high nickel and chromium contain shall be applied in this area. Due to fact, that by this way manufactured material has diametrically different microstructure, it is necessary to verify its properties.

This article deals with, in particular, mechanical and microstructural properties of products (test specimens) from Steel AISI 316L produced by 3D printing (SLM method). Assessments of the strength parameters in the tensile test, the impact energy and hardness are studied. For the assessment of basic microstructure, porosity and fracture surfaces evaluation the light microscopy is used. Obtained results are compared with the properties of identical test specimens made by "conventional" ways. The results show promising and homogenous mechanical properties.
\end{abstract}

Keywords: 3D print, SLM, steel AISI 316L, microstructure, mechanical properties

\section{INTRODUCTION}

Modern production methods include the technology called as 3D printing. This method has been recently used in the processing of metallic materials. The application excels especially where conventional technology manufacturing (casting, rolling, machining) are failing in terms of complexity of the product shape, low production numbers, energy and environmental difficulty [1-5]. One of the so-called additive 3D printing methods of metal materials is Selective laser melting (SLM).

This method produces objects according to the CAD model by using a laser beam with a high performance, which melts and joins the atomized metal powder in the specified location. Creating 2D layers that gradually joins (deposits) at each other until the appearance of the final 3D product. SLM finds application in the production of the highly shaped and internally structured parts, that classic technological procedures make it very difficult, or even impossible. SLM method, however, is dependent on a large number of parameters (laser power, texture of plating layers, cooling and heat dissipation), which greatly affects the quality of the product. Therefore, it is necessary to consistently monitored all sorts of mechanical, physical and functional characteristics of the products thus obtained [3-6].

One of the frequently used materials for the SLM is an austenitic stainless steel 1.4404 (AISI 316L By combination its mechanical and corrosive properties, this steel is widely used in the medical, energetics and food applications. This paper in practical part deals with the characteristics of the products produced by the SLM from this steel. Furthermore, is paper focused to a comparison of the wider spectrum of properties of test specimens made using 3D printing and "conservative" or "conventional" procedures (machining from the rolled sheet, etc.) [5-9]. 


\section{MATERIAL AND TESTING METHODS}

Available were flat specimens for tensile testing from the Steel AISI 316L. Those were taken from metal sheet for medical applications with high homogeneity. On the other side there were same size specimens produced by SLM method, where input powder (diameter of powder particles was $45 \pm 15 \mu \mathrm{m}$ ) was prepared by melt atomizing in inert gas. The chemical composition, comparison and results of EDX verification are in Table 1.

Table 1 Chemical composition of the steel AISI 316L

\begin{tabular}{|c|c|c|c|c|c|c|c|c|c|}
\hline Element [wt.\% ] & $\mathbf{C}$ & $\mathbf{S i}$ & $\mathbf{M n}$ & $\mathbf{P}$ & $\mathbf{S}$ & $\mathbf{C r}$ & $\mathbf{M o}$ & $\mathbf{N i}$ & $\mathbf{N}$ \\
\hline 316L conventional & 0.03 & $\begin{array}{c}1.00 \\
\max \end{array}$ & $\begin{array}{c}2.00 \\
\max \end{array}$ & $\begin{array}{c}0.025 \\
\max \end{array}$ & $\begin{array}{c}0.010 \\
\max \end{array}$ & $17.0-19.0$ & $2.50-3.20$ & $13.0-15.5$ & $\begin{array}{c}0.10 \\
\max \end{array}$ \\
\hline $\begin{array}{c}316 \mathrm{~L} 3 \mathrm{D} \\
\text { powder producer }\end{array}$ & $\begin{array}{c}0.03 \\
\max \end{array}$ & $\begin{array}{c}1.00 \\
\max \end{array}$ & $\begin{array}{c}2.00 \\
\max \end{array}$ & $\begin{array}{c}0.045 \\
\max \end{array}$ & $\begin{array}{c}0.03 \\
\max \end{array}$ & $16.0-18.0$ & $2.00-3.00$ & $10.0-14.0$ & $\begin{array}{c}0.10 \\
\max \end{array}$ \\
\hline $\begin{array}{c}316 \mathrm{~L} 3 \mathrm{D} \\
\text { EDX verification }\end{array}$ & - & 0.86 & 0.67 & - & - & 17.39 & 2.68 & 12.27 & - \\
\hline
\end{tabular}

As 3D printing machine Renishaw AM400 has been used. Melting rate of the material is $5-20 \mathrm{~cm}^{3} / \mathrm{h}$. Geometrical accuracy is $\pm 50 \mu \mathrm{m}$ and scan speed $2000 \mathrm{~mm} \cdot \mathrm{s}^{-1}$. Positioning speed of the laser is $7000 \mathrm{~mm} / \mathrm{s}$. Layer thickness is from 20 to $100 \mu \mathrm{m}$. The diameter of the laser beam reaches $70 \mu \mathrm{m}$ and the used laser power was $200 \mathrm{~W}$. The form of flat specimens for tensile test made by 3D way is shown in Figure 1; their parameters are in the Table 2. The dimensions of the specimen test section (cross section of the smallest was $1.5 \mathrm{~mm} \times 5 \mathrm{~mm}$ ) were minimized to be sensitive to the possible weaknesses of 3D printing (porosity, etc.) The final product (surface) wasn't further processed mechanically or thermally. Three pices of samples of each type were available. Total were 9 pieces of samples tested produced by SLM and 9 produced by conventional methods - cold rolled and normalized. Tensile testing machine was Zwick/Roell Z150 with extensometer.

Table 2 Dimensions of tensile test specimens

\begin{tabular}{|c|c|c|c|c|c|}
\hline Specimen type & $\begin{array}{c}\text { a [mm] } \\
\text { - thickness }\end{array}$ & b [mm] & b/a [mm] & Lc [mm] & L [mm] \\
\hline A & 2.9 & 9.7 & 3.34 & 40 & 140 \\
\hline B & 1.95 & 6.5 & 3.33 & 30 & 80 \\
\hline C & 1.45 & 4.85 & 3.34 & 25 & 80 \\
\hline
\end{tabular}

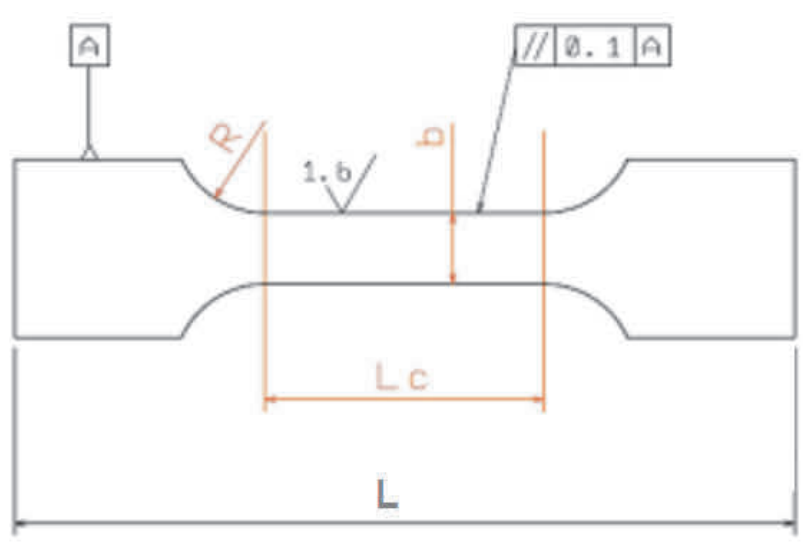

Figure 1 The scheme of tensile test specimens

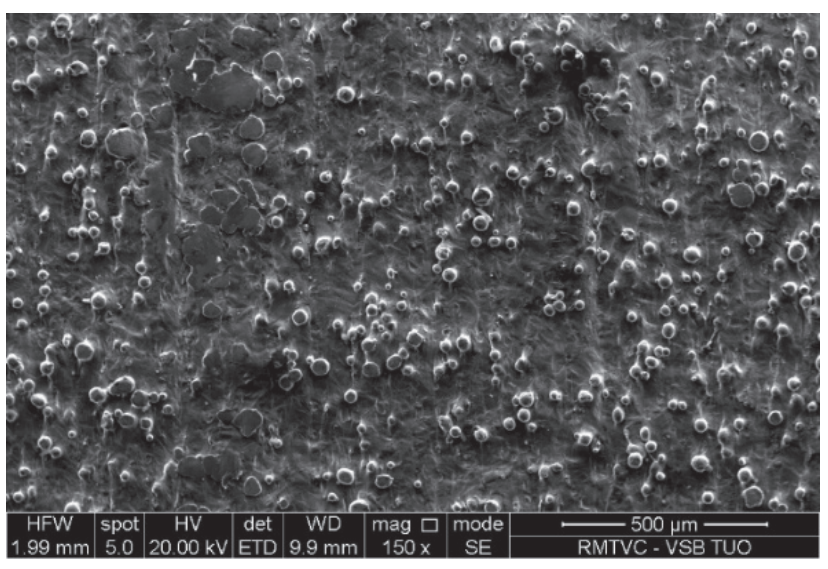

Figure 2 Surface of 3D printed specimens 
In the field of the mechanical properties were evaluated the strength properties, hardness by Vickers HV30 and impact bending test (standard specimens with $2 \mathrm{~mm} \mathrm{V-notch} \mathrm{machined).} \mathrm{To} \mathrm{characterization} \mathrm{of} \mathrm{the} \mathrm{surface}$ quality, the roughness was tentatively Figure 2.

Metallographic microstructure assessment was observed by light and electron (SEM) microscopy. Evaluated were also basic fractography of fracture surfaces and porosity (by picture analysis) classification. Specimens obtained this way were prepared for microstructure observation by standardized metallographic methods grinding, polishing. Microstructure was developed by solution „V2“( $10 \mathrm{HCl}: 1 \mathrm{HNO}_{3}: 10 \mathrm{H}_{2} \mathrm{O}$ - volume parts). Scratch patterns have been prepared parallel to the plane of the surface (or the surface of the sheet). Were used light microscope Olympus IX70. SEM and EDS analysis proceeded by SEM microscope JEOL JSM6490LV with EDAX analyser.

\section{RESULTS AND DISCUSSION}

As the first, tensile tests of both sets of specimens were performed. The results are shown in Table 3. Due to the almost identical tests development for each set of specimens are always listed average values of all measured quantities. The tests progress as graphic dependence stress - strain is in Figure 3.

Table 3 The results of tensile tests

\begin{tabular}{|c|c|c|c|c|c|}
\hline Specimen type & $\begin{array}{c}\mathbf{E} \\
{[\mathrm{GPa}]}\end{array}$ & $\begin{array}{c}\text { YS\{p0.2\} } \\
{[\mathrm{MPa}]}\end{array}$ & $\begin{array}{c}\text { UTS } \\
{[\mathrm{MPa}]}\end{array}$ & $\begin{array}{c}\mathbf{A}_{5} \\
{[\%]}\end{array}$ & $\mathbf{Z}$ \\
{$[\%]$} & 25.03 & 54 \\
\hline A 3D & 207 & 525 & 771 & 10.36 & 48 \\
\hline A conventional & 207 & 770 & 638.2 & 26.93 & 50 \\
\hline B 3D & 208 & 522 & 1019 & 10.06 & 47 \\
\hline B conventional & 207 & 783 & 631 & 23.30 & 49 \\
\hline C 3D & 208 & 509 & 907 & 14.54 & 50 \\
\hline
\end{tabular}

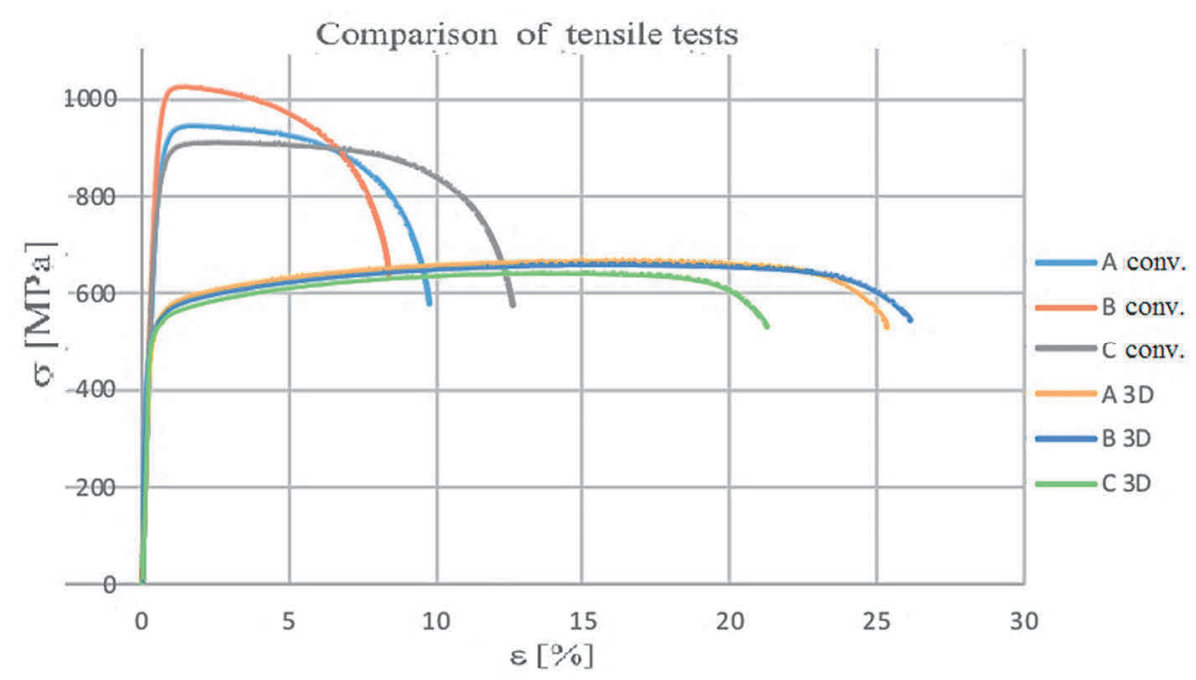

Figure 3 Stress - strain diagram, comparison between SLM and conventional specimens

The progress of the tests showed very homogeneous properties for both series of materials. Strength properties are for all types of test specimens prepared by 3D print nearly identical and reach approximately $70 \%$ of the properties to the conventional samples: yield strength 509 till $525 \mathrm{MPa}$ against 720 till $780 \mathrm{MPa}$, tensile strength 630 till $670 \mathrm{MPa}$ against 907 till $1019 \mathrm{MPa}$. Paradoxically, the larger differences in the results 
are evident in the conventional samples. In particular, the strength of the type B test specimens was significantly higher compared to $\mathrm{A}$ and $\mathrm{C}$ type, which appears to be related with the production of the input sheet. Elongation for 3D printed specimens is more than doubled - 23 to $26 \%$, compared to 10 to $14 \%$ for conventional specimens. The calculated E-modulus is nigh identical.

The significant porosity $[9,10]$ or roughness influence on material are proved fake. The surface morphology of the 3D printed specimens is characterized by the appearance of smelting globules (drops) with a uniform distribution (see Figure 2). The measured surface roughness is given by the parameter $\mathrm{Ra}=5.3$ to $5.4 \mu \mathrm{m}$ for the 3D printed test specimens. The surface of the conventionally produced specimens showed a roughness $\mathrm{Ra}=0.10$ to $0.13 \mu \mathrm{m}$. Results of indicative hardness tests HV30 and impact bending test are summarized in Table 4. Hardness corresponds with the measured strength characteristics and for $3 \mathrm{D}$ print specimens is approximately two thirds. Impact energy values are very similar for both of production ways.

Table 4 The results of hardness and impact energy measurement

\begin{tabular}{|c|c|c|}
\hline Steel AISI 316L & HV30 & CVN [J] \\
\hline 3D printed & 217 & 113 \\
\hline Conventional & 308 & 120 \\
\hline
\end{tabular}

Metallographic observation has shown on samples in polished condition relatively low square porosity in the range of 0.1 to $0.3 \%$ (see two areas in Figure 4). Figure 5 shows pores on the fracture surface of tensile test specimen with using of SEM.

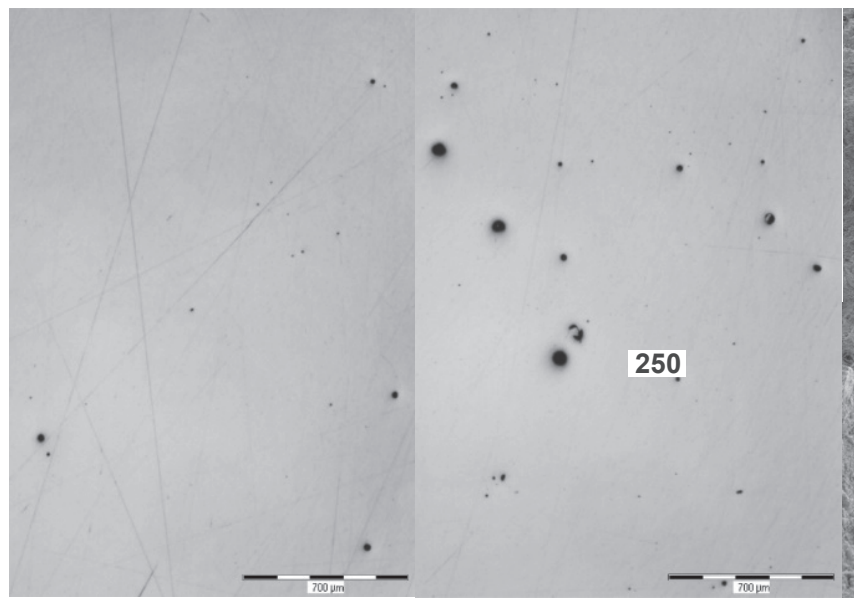

Figure 4 Porosity on polished surface

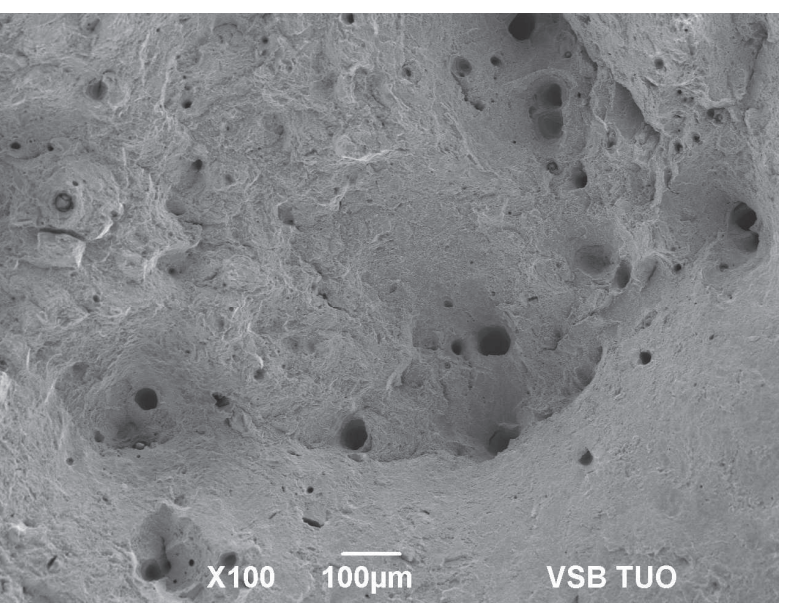

Figure 5 Porosity on fracture surface (SEM)

Microstructure of AISI 316 L steel produced by 3D printing is significantly different from conventionally produced material [11]. It has a distinctive texture and is made up of parallel stripes of melt powder. Individual "threads" are placed in layers, the direction of the threads is turn of $67^{\circ}$ angel with each layer (optimization on the basis of experience from production). Microstructure consists of austenitic grains that are grow (penetrate) into individual threads. In the structure was observed fine dissolving (dendritic segregation). Figures 6a) to 6c) are typical examples of microstructure at different magnifications. Figure 6d) then shows comparison standard austenitic microstructure of conventional sample with visible traces of plastic deformation after forming (rolling).

The fracture surfaces of every tensile test specimens have a signs of ductile fracture [12]. However at 3D printed materials (see Figures $\mathbf{7 a}$ )-c)) is the character of the quarry much finer (Figure $\mathbf{7 b}$ ) than at conventional specimens (Figure 7d). It is evident that the propagation of the fracture is affected by pore incurred during 3D printing. A more detailed view of the fracture surface of 3D specimens is in Figure 7a). Figure $\mathbf{7 d}$ ) documents with smaller magnification a global view on a fracture of the conventional specimen 
with evident middle discontinuity. Probably it has origins in the so-called kiss-point of original cast sheet. In both cases, there is a high - energetic ductile dimple fracture [12]. This indicates relatively good toughness of both materials. The creation of these dimples is an asynchronous failure of material caused by shear stress. The size of these dimples reflects the state of the microstructure, grain size respectively.
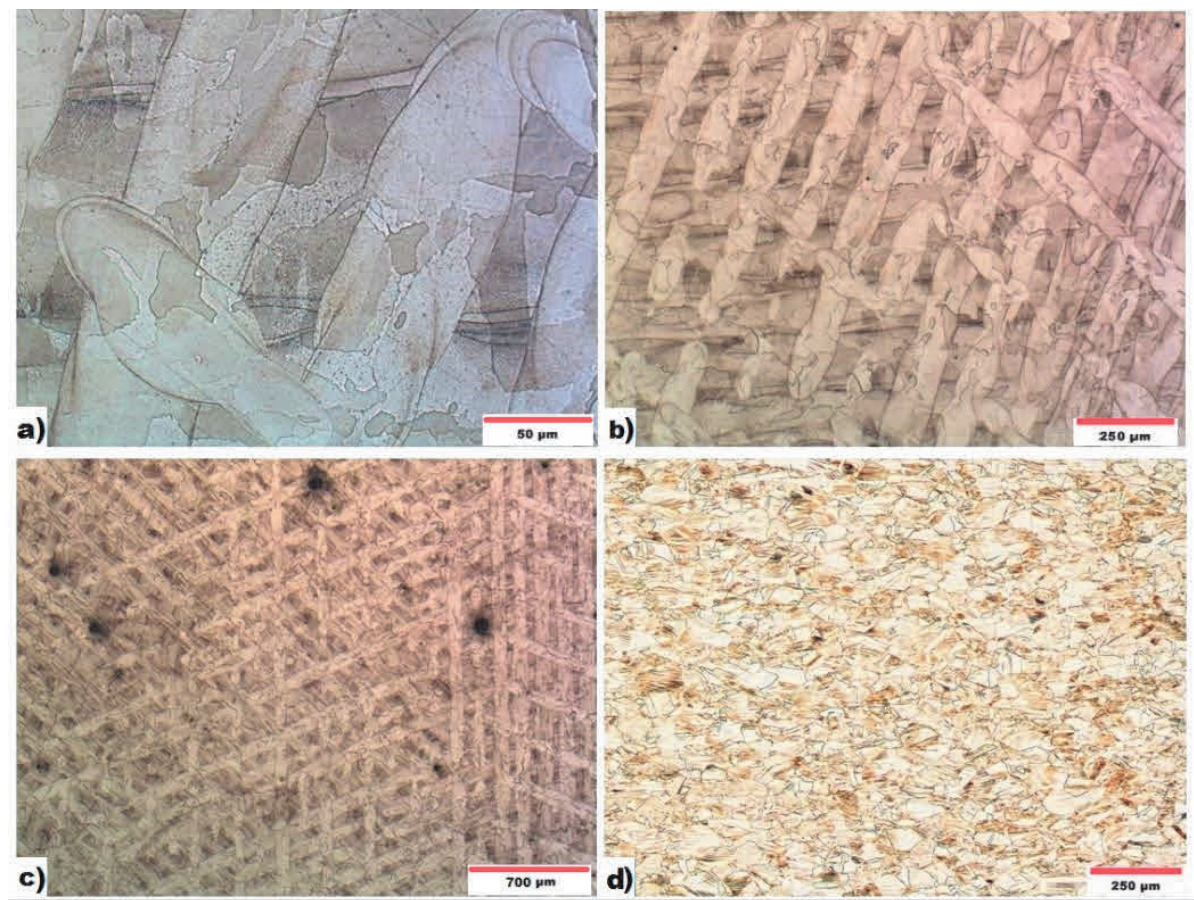

Figure 6 The microstructure of AISI 316 L: a - c) 3D printed; d) "conventional"
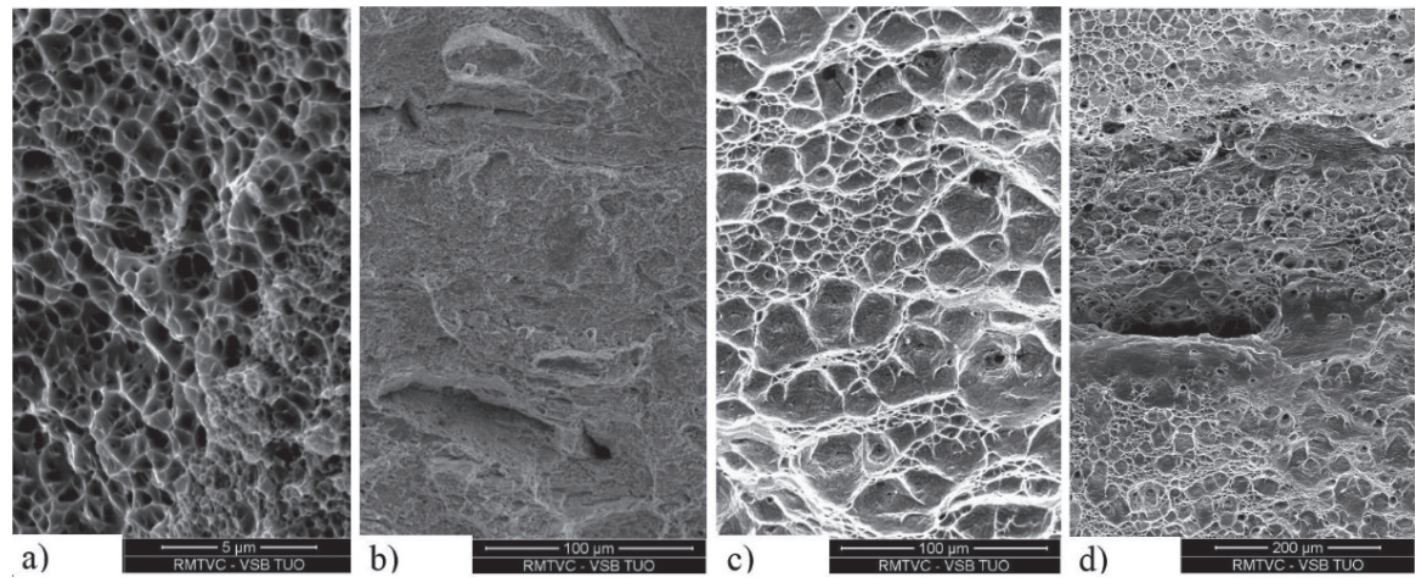

Figure 7 Fracture surfaces of tensile test specimens: a, b) 3D printed; c, d) "conventional"

\section{CONCLUSION}

Microstructure character of the specimens prepared by 3D printing diverges significantly from the conventional material and has a striking texture. However, it is a very regular, made up of austenite and has a relatively low porosity $(0.1$ to $0.3 \%)$. Tensile test has proved very homogeneous properties for each series of samples. Concerning the influence of the original untreated surface roughness and porosity this was not confirmed. In comparison with conventional specimens achieves the yield strength and the tensile strength of the SLM prepared specimens approximately $70 \%$ level (for a specimens C is UTS $630 \mathrm{MPa}$ versus $910 \mathrm{MPa}$ ). Elongation is significantly higher (about $25 \%$ ), than in conventional samples (14 \% max.). The hardness is 
210 HV30 for SLM specimens and 310 HV30 for conventional specimens. The fracture surfaces have the very fine ductile character with the influence of defects (porosity).

The achieved results are promising and indicate that $3 \mathrm{D}$ printing technology is progressive. For the future is the need to develop the study of materials prepared by those methods materials e.g. towards the fatigue characteristics [13], and other mechanical characteristics that will show significance of 3D printing of metals. For a detailed assessment of the microstructure will need to use other methods, e.g. EBSD. A wide field of research also opens in the field of post-production processes such as optimization of heat treatment, machining, forming, etc.

\section{ACKNOWLEDGEMENTS}

This paper created with the contribution of the projects Student Grant Competition "SP2019/27 Application of structural analysis, mechanical property testing and non-destructive defectoscopy methods at complex characterization of advanced materials" and "SP2019/43 Specific research in the metallurgical, materials and process engineering".

This paper was created in the Project LTI17023 "Energy Research and Development Information Centre of the Czech Republic" funded by Ministry of Education, Youth and Sports of the Czech Republic, program INTER-EXCELLENCE, subprogram INTER-INFORM.

\section{REFERENCES}

[1] BARNATT, Christopher. 3D printing: the next industrial revolution. 2nd ed. CreateSpace Independent Publishing Platform, 2013. p. 276.

[2] MA, Chim, DONG, Yalin and YE, Chang.Improving Surface Finish of 3D-printed Metals by Ultrasonic Nanocrystal Surface Modification. Procedia CIRP. 2016. vol. 45, pp. 319-322.

[3] OSAKADA Kozo, SHIOMI Masanori. Flexible manufacturing of metallic products by selective lasermelting of powder. International Journal of Machine Tools and Manufacture. 2006, vol. 46, no. 11, pp. 1183-93.

[4] DAS, Suman, BOURELL, DAVID L. and BABU S.S. Metallic materials for 3D printing. MRS Bulletin. 2016. vol. 41, pp. 729-741.

[5] MURR, Lawrence E. and JOHNSON, Wayne L. 3D metal droplet printing development and advanced materials additive manufacturing. Journal of Materials Research and Technology. 2017. vol. 6, no. 1, pp. 77-89.

[6] KRUTH, Jean-Pierre, L. FROYEN, Ludo. Van VAERENBERGH, Jozef. and ROMBOUTS, Marleen Selective laser melting of iron-based powder. Journal of Materials Processing Technology. 2004. vol. 149, pp. 616-622.

[7] MÄKINEN, Mika at al. Preliminary Comparison of Properties between Ni-electroplated Stainless Steel Parts Fabricated with Laser Additive Manufacturing and Conventional Machining. Physics Procedia. 2015. vol 75, pp. 337-346.

[8] DEEV, A. A., KUZNETCOV, P. A. and PETROV, S. N. Anisotropy of mechanical properties and its correlation with the structure of stainless steel 316L by SLM method. Physics Procedia. 2016. vol. 83, pp. 789 - 796.

[9] NESMA, Aboulkhair, T., EVERITT, Nicola, M., ASHCROFT, I. and TUCK, Chris. Reducing porosity in AISi10Mg parts processed by selective laser melting. Additive Manufacturing. 2014. vol. 1- 4, pp. 77-86.

[10] HEINL, Peter, MÜLLER, Lenka, KÖRNER, Carolin. SINGER, Robert and MÜLLER, Frank A. Cellular Ti-6AI-4V structures with interconnected macro porosity for bone implants fabricated by selective electron beam melting. Acta Biomaterialia. 2008, no 4, pp. 1536-1544.

[11] PORTER, David A., EASTERLING, Kenneth E. and SHERIF, Mohamed. Phase Transformations in Metals and Alloys. 3rd ed., CRC Press, 2009. p. 536.

[12] MCEVILLY, Arthur J. Metal Failures, Mechanism, Analysis, Prevention. 2nd ed. New York: Wiley and Sons, 2013. p. 504.

[13] RIEMER, Andre, LEUDERS, Stefan, RICHARD, Hans A., TROSTER, Thomas and NIENDORF, Thomas. On the fatigue crack growth behavior in $316 \mathrm{~L}$ stainless steel manufactured by selective laser melting. Engineering Fracture Mechanics. 2014. vol. 120, pp. 15-25. 